\title{
Renal Evaluation in Women with Preeclampsia
}

\author{
T.A. Facca G. Mastroianni Kirsztajn A.R. Pereira S.R. Moreira \\ V.P.C. Teixeira S.K. Nishida N. Sass
}

Disciplines of Obstetrics and Nephrology of the Federal University of São Paulo (UNIFESP), São Paulo, Brazil

\section{Key Words}

Albuminuria $\cdot$ Podocytes $\cdot$ Preeclampsia $\cdot$ Proteinuria $\cdot$ Retinol-binding proteins

\begin{abstract}
Background/Aims: Preeclampsia (PE) is a cause of glomerulopathy worldwide. Urinary retinolbinding protein (RBP) is a marker of proximal tubular dysfunction, albuminuria is an endothelial injury marker, urine protein:creatinine ratio (PCR) may have a predictive value for renal disease later in life, and, recently, podocyturia has been proposed as a sensitive tool in pregnancy, but it needs to be tested. The aim of this study was to evaluate renal involvement in PE and healthy pregnancy. Methods: Case-control study with 39 pregnant women assessed after 20 weeks of gestation ( 25 in the control group, CG, and 14 in the PE group) by performing urinary tests. Results: Mean ( \pm SD) age and gestational age of the CG were $26.9 \pm 6.4$ years and $37.1 \pm$ 5.0 weeks, and of the PE group $26.4 \pm 6.9$ years and $30.6 \pm 5.6$ weeks, respectively $(p=0.001)$. Mean $( \pm S D)$ urinary RBP $(p=0.017)$, albuminuria $(p=0.002)$, and urinary albumin concentration (UAC) ratio $(p=0.006)$ of the CG were $0.4 \pm 0.7 \mathrm{mg} / \mathrm{l}, 7.3 \pm 6.9 \mathrm{mg} / \mathrm{l}$, and $8.2 \pm 6.7 \mathrm{mg} / \mathrm{g}$ and of the PE group $2.0 \pm 4.4 \mathrm{mg} / \mathrm{l}, 2,267.4 \pm 2,130.8 \mathrm{mg} / \mathrm{l}(\mathrm{p}=0.002)$, and 3,778.9 $\pm 4,296.6 \mathrm{mg} / \mathrm{g}$ $(p=0.006)$, respectively. Mean $( \pm S D)$ urine PCR in the PE group was $6.7 \pm 6.1 \mathrm{~g} / \mathrm{g}(\mathrm{p}<0.001)$. No statistical differences were found between podocyturia in the CG and PE group $(p=0.258)$. Conclusions: Urinary RBP, PCR, albuminuria, and UAC ratio were elevated in the PE group in comparison to the CG. Podocyturia did not predict PE.




\section{Introduction}

Preeclampsia (PE) occurs in $3-10 \%$ of all pregnancies $[1,2]$ and is a major cause of maternal and fetal morbidity and mortality $[3,4]$. It is a multisystem disease exclusive to pregnancy and is defined as hypertension $(\geq 140 / 90 \mathrm{~mm} \mathrm{Hg}$ ) and proteinuria $(\geq 300 \mathrm{mg} / 24 \mathrm{~h}$ or $\geq 1+$ in dipstick urinalysis) after 20 weeks of gestation. It can persist until 12 weeks after labor.

Hypertension in pregnancy can be manifest in different clinical forms: gestational hypertension, PE, eclampsia, or gestational hypertension and preeclampsia superimposed with chronic hypertension $[5,6]$.

$\mathrm{PE}$ is associated with many serious complications during pregnancy. These are eclampsia, brain edema, stroke, posterior reversible encephalopathy syndrome, and HELLP syndrome (hemolysis, elevated liver enzymes, and low platelet count) [7]. Moreover, PE may be related to future increased cardiovascular risk [8] and also renal disease [9].

Cardiovascular disease (CVD) and PE apparently have similar pathophysiological mechanisms as both are associated with endothelial dysfunction, metabolic syndrome, oxidative stress, and share some similar risk factors such as obesity, smoking, advanced age, renal disease, and diabetes [10]. The exact relationship between PE and CVD has not been elucidated; the metabolic stress triggered by PE probably induces vascular injury that contributes to the onset of CVD [11] and even the future risk of chronic kidney disease (CKD) [12].

Despite extensive study of PE, its etiopathogenesis has not been totally elucidated. Possible mechanisms of PE include inadequate placentation leading to an inadequate uteroplacental perfusion with subsequent tissue hypoxia and oxidative stress, triggering the release of antiangiogenic factors in the maternal circulation causing a systemic inflammatory reaction. Further, these factors trigger generalized endothelial dysfunction which is responsible for the hypertensive syndrome [13, 14].

Endothelial dysfunction in PE occurs because of the imbalance of its homeostasis. Proangiogenic factors such as PlGF (placental growth factor) and VEGF (vascular endothelial growth factor) are inhibited by the action of other factors probably originated by the hypoxia of the cytotrophoblast. The main anti-angiogenic factors are sEng (soluble endoglin) and sFlt-1 (soluble vascular endothelial growth factor) [15-18].

VEGF plays also an important role in glomerular filtration as a protective factor against structural podocyte damage allowing its proper function in the endothelium [19, 20]. Harm to the podocyte is directly related to the renal involvement in PE [21], as injury leads to the loss of its interdigitation, a dedifferentiation process, and deficient adhesion to the glomerular basement membrane with consequent urinary podocyte excretion and development of glomerulosclerosis [22].

Proteinuria is probably the main cause of progression of renal disease in PE [23], and its level is directly related to a poor maternal and perinatal outcome [24]. Microalbuminuria is a renal endothelial injury marker resulting from systemic or renal vascular damage, is associated with increased cardiovascular risk especially in hypertensive and diabetic individuals, and is one of the main tests for screening CKD [25]. Thus, persistent microalbuminuria or proteinuria after PE may represent a greater risk for CVD and CKD [26].

The complications of PE can be prevented if detected early. Diagnosis of renal disorders after PE may allow prompt initiation of treatment. Early renal screening is essential to improve long-term outcome and reduce the pregnancy risks. This study was designed to better understand this disorder and its tubular and glomerular repercussions by evaluating urinary markers in PE and a control group (CG). 


\section{Materials and Methods}

This was a case-control study with a total of 39 pregnant women after 20 weeks of gestation, 25 in the CG and 14 in the PE group, assessed by renal parameters such as podocyturia, proteinuria, albuminuria, urinary albumin concentration (UAC) ratio, urinary retinol-binding protein (RBP), and urine protein:creatinine ratio (PCR). This study was approved by the Ethics Committee of the Federal University of São Paulo (UNIFESP).

The study population consisted of women from maternity hospitals located in the metropolitan region of São Paulo who were hospitalized because of PE, and the CG included corresponding healthy pregnant women who also attended those hospitals.

The PE group was composed of women diagnosed according to the research definition criteria established by the National High Blood Pressure Education Program (NHBPEP, 1990) [5]. The CG were healthy pregnant women with no history of hypertension at any time of life. To define the HELLP syndrome, we used the criteria of Sibai, 1990 [27]: hemolysis (abnormal peripheral smear, total bilirubin $>1.2 \mathrm{mg} / \mathrm{dl}$ and/or lactate dehydrogenase $>600$ $\mathrm{IU} / \mathrm{l}$ ), elevated liver enzymes (glutamic oxaloacetic transaminase, glutamic pyruvic transaminase $>70 \mathrm{IU} / \mathrm{l}$ ), and thrombocytopenia (platelets $<100,000 / \mathrm{mm}^{3}$ ).

The following parameters were assessed in all selected women: age (years), gestational age (weeks), body mass index (BMI; $\mathrm{kg} / \mathrm{m}^{2}$ ) pre-pregnancy and in the current pregnancy, urine $\mathrm{PCR}$, random protein $(\mathrm{g} / \mathrm{l})$ creatinine $(\mathrm{g} / \mathrm{l})$ ratio, urinary RBP $(\mathrm{mg} / \mathrm{l})$, albuminuria $(\mathrm{mg} / \mathrm{l})$, $\mathrm{UAC}$ ratio $(\mathrm{mg} / \mathrm{g})$, urinary total cell number, podocyturia, and podocyte/total cells ratio (\%).

We excluded patients with multiple pregnancy, diabetes mellitus, previously diagnosed kidney disease, autoimmune diseases, current urinary tract infection, previously detected microalbuminuria, and a history of hypertension or proteinuria.

All patients were given an explanation about this study and signed the informed consent form.

Urine samples were collected and frozen at $-20^{\circ} \mathrm{C}$. All samples were sent to the laboratory of the Kidney and Hypertension Hospital, UNIFESP, for analysis of albuminuria, random proteinuria, urine PCR, urinary RBP, and UAC ratio. Albuminuria and proteinuria were evaluated by immunoturbidimetric method, the urinary RBP by enzyme immunoassay using monoclonal antibodies, and urine creatinine by the alkaline picrate colorimetric method.

Microalbuminuria in random urine samples was considered positive for values between 30 and $300 \mathrm{mg} / \mathrm{l}$, and macroalbuminuria was defined above this level [28]. Urinary RBP was elevated when $>0.4 \mathrm{mg} / \mathrm{l}$ [29]. The cutoff adopted for urine PCR was 0.14 [30]. The cutoff for $\mathrm{UAC}$ ratio was $30 \mathrm{mg} / \mathrm{g}$ [31].

\section{Podocyturia}

Podocytes were detected in random urine samples $(6 \mathrm{ml})$ fixed with absolute ethyl alcohol $99.5 \%(1: 1)$ and stored at $4^{\circ} \mathrm{C}$. The urine sample was centrifuged for $10 \mathrm{~min}$ at 1,000 r.p.m. in the centrifuge LS-3 plus (Celm, Brazil) and cytocentrifuged in the CT-12 (Presvac, Brazil) for $5 \mathrm{~min}$ at 500 r.p.m. at room temperature, and then frozen at $-20^{\circ} \mathrm{C}$. The slide was fixed for $10 \mathrm{~min}$ at room temperature with formaldehyde $2 \%$, and then washed for $5 \mathrm{~min}$ with PBS (phosphate-buffered saline). The slide was incubated with $0.3 \%$ Triton for $10 \mathrm{~min}$ at room temperature and washed for $5 \mathrm{~min}$ in PBS. The slide was incubated for $60 \mathrm{~min}$ with blocking solution consisting of PBS with BSA (bovine serum albumin) $0.2 \%, \mathrm{NH}_{4} \mathrm{Cl} 50 \mathrm{mM}$, and goat serum $1 \%$ at room temperature followed by rabbit IgG anti-nephrin polyclonal antibody H-300 sc-28192 (Santa Cruz Biotechnology, USA) dilution 1:50 in PBS and BSA overnight at $4^{\circ} \mathrm{C}$ and washed for $10 \mathrm{~min}$ with PBS. The slide was incubated for $45 \mathrm{~min}$ at room temperature with fluorescein (FITC) anti-rabbit IgG secondary antibody (Santa Cruz Biotechnology) dilution 1:100 in PBS and BSA. Then Vectashield (mounting medium for fluorescence) with 
Fig. 1. Podocyturia in PE by immunofluorescence techniques using rabbit IgG anti-nephrin polyclonal antibody. Positive nucleus (blue staining); positive cytoplasm (green staining). Parietal epithelia cell (high cytoplasm/nucleus ratio); podocyte cell (low cytoplasm/nucleus ratio).

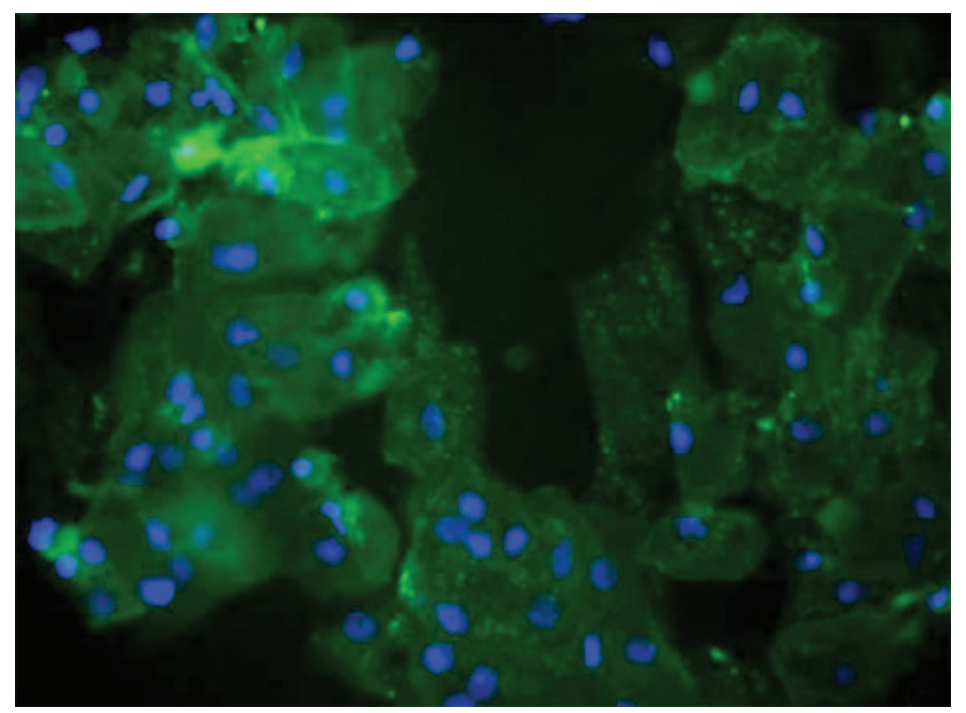

DAPI (4'6-diamino-2-phenylindole dihydrochloride) was applied (H-1200 Vector Laboratories, Inc., USA).

The detection of podocytes was performed by an experienced observer, who was blinded to which group the slide belonged, by immunofluorescence techniques as shown in figure 1. The podocytes and the total number of cells were counted in 15 fields photographed under $400 \times$ magnification with a digital camera coupled to an epifluorescence microscope DM1000 (Leica, Germany) connected to a computer. The results were expressed as podocyte/ total cells (\%) per area of higher cell concentration (hot spots) in the field of $400 \times$ detected by the positive nuclear and cytoplasmic staining.

\section{Statistics}

The calculation of mean, median, minimum, maximum, and standard deviation was performed for quantitative variables. The qualitative variables were analyzed by calculating the absolute and relative frequency (percentage). The statistical analysis between the CG and $\mathrm{PE}$ group according to race, parity, history of $\mathrm{PE}, \mathrm{BMI}$ classification, smoking, and proteinuria (dipstick urinalysis) was performed using $\chi^{2}$ test, Fisher's exact test or its extension. The Student's $t$ test was used for independent samples such as age, BMI, albuminuria, UAC ratio, and the number of total cells. The Mann-Whitney $U$ test was used for gestational age, urine PCR, random proteinuria, urinary RBP, podocyte cells, and podocyte/total cells ratio. Point estimation and interval of sensitivity, specificity, and area under the ROC curve were used to obtain the cutoff points for urine PCR and UAC ratio, with the goal of predicting PE. Point estimation and interval of the Pearson correlation coefficient between 24-hour proteinuria and podocyte/total cells ratio in PE was calculated. For all the results obtained through the analysis we used a significance level of $\alpha=5 \%$. Data were entered into Excel spreadsheets for Windows 2010. Statistical analysis was performed with the R-software version 2.11.0.

\section{Results}

The sample selected for this study consisted of 39 women, 35.9\% (14/39) with PE and 64.1\% (25/39) without PE. All control subjects were negative for proteinuria (dipstick urinalysis) and none of the subjects in the PE group had negative results for proteinuria by dip- 
Table 1. Demographic data

\begin{tabular}{lccc}
\hline & Control group & PE group & $\mathrm{p}$ \\
\hline Patients, $\mathrm{n}$ & 25 & 14 & - \\
Age, years & $26.9 \pm 6.4$ & $26.4 \pm 6.9$ & 0.799 \\
Caucasian ethnicity & $11 / 25(44.0 \%)$ & $9 / 14(64.3 \%)$ & 0.224 \\
Primiparous & $10 / 25(40.0 \%)$ & $10 / 14(71.4 \%)$ & 0.060 \\
Past history of PE & $1 / 25(4.0 \%)$ & $3 / 14(21.4 \%)$ & 0.123 \\
Smokers & $3 / 25(12.0 \%)$ & $2 / 14(14.3 \%)$ & $>0.999$ \\
Normal BMI pre-pregnancy & $17 / 29(68.0 \%)$ & $8 / 14(57.1 \%)$ & 0.41 \\
Normal BMI current pregnancy & $13 / 25(52.0 \%)$ & $3 / 14(21.4 \%)$ & 0.237 \\
Gestational age, weeks & $37.1 \pm 5.0$ & $30.6 \pm 5.6$ & 0.001 \\
\hline
\end{tabular}

stick urinalysis. A comparison of the baseline data for age, ethnicity, primiparity, previous pregnancy history, BMI, and gestational age is given in table 1 .

The total number of cells in the urine in the CG was $346.1 \pm 327.2$ cells/hot spots and in the PE group $467.9 \pm 549.1$ cells/hotspots $(\mathrm{p}=0389)$. For podocyturia, the mean total number of podocytes in the CG was $0.9 \pm 1.6$ and in the PE group $9.3 \pm 16.8(\mathrm{p}=0.212)$. Also, in the CG we found $0.5 \pm 0.8$ podocytes/total number of cells (\%) and in the PE group $1.2 \pm 1.7(\mathrm{p}=0.258)$.

Urine PCR and random proteinuria were both $0.0 \pm 0.0$ in the CG, and in the PE group $6.7 \pm 6.1 \mathrm{~g} / \mathrm{g}(\mathrm{p}<0.001)$ and $4.4 \pm 4.3 \mathrm{~g} / \mathrm{l}(\mathrm{p}<0.001)$, respectively. Also statistically significant were: urinary RBP, which was $0.4 \pm 0.7 \mathrm{mg} / \mathrm{l}$ in the CG and $2.0 \pm 4.4 \mathrm{mg} / \mathrm{l}$ in the PE group $(\mathrm{p}=0.017)$, albuminuria, which was $7.3 \pm 6.9 \mathrm{mg} / \mathrm{l}$ in the $\mathrm{CG}$ and 2,267.4 $\pm 2,130.8$ $\mathrm{mg} / \mathrm{l}$ in the PE group ( $\mathrm{p}=0.002)$, and UAC ratio, which was $8.2 \pm 6.7 \mathrm{mg} / \mathrm{g}$ in the CG and $3,778.9 \pm 4,296.6 \mathrm{mg} / \mathrm{g}$ in the PE group $(\mathrm{p}=0.006)$.

Twenty-four-hour proteinuria as well as the following blood tests were collected only for women in the PE group: hemoglobin, platelets, LDH, AST, ALT, urea, and serum creatinine. The PE group was investigated for 24-hour proteinuria, but only 9 of 14 (64.2\%) individuals in this group completed this evaluation because of inadequate volume collection or interruption by labor.

There seems to be no relationship between levels of 24-hour proteinuria and podocytes/ total cells ratio. This was confirmed by the estimates of Pearson's correlation coefficients (0.0188; $95 \%$ CI -0.593 to 0.725$)$. Because of the small sample size (only 9 pregnant women), the interval estimate of the correlation coefficient is inaccurate.

As shown in the comparison of these markers between the CG and the PE group, urine PCR and UAC ratio are good predictors of PE. The same observations were not possible based on the podocyte/total cells ratio due to low values of sensitivity and specificity.

\section{Discussion}

Our study demonstrated that women with PE had higher urinary RBP in comparison to the CG. We also found elevated levels of albuminuria and total proteinuria. All patients with $\mathrm{PE}$ had increased urine PCR and UAC ratio.

$\mathrm{RBP}$ is a novel adipokine mainly synthesized by the liver which is strongly associated with inflammation, obesity, and insulin resistance. RBP4 is a plasma protein that seems to have no correlation with maternal age, gestational age, pre-pregnancy BMI, and neonatal birth weight. It is decreased in acute stress conditions, such as pyelonephritis [32], though it 
is elevated in PE in comparison to normal pregnancy, specifically in early-onset PE [33]. $\mathrm{RBP} 4$ and insulin resistance index are both higher in overweight pregnant women with lateonset PE when compared with a CG, which suggests that RBP might act in the pathophysiology of vascular dysfunction in PE [34].

Excretion of RBP increases during pregnancy, and it is especially higher in the second and third trimesters than in the first [35]; however, RBP4 remains within normal levels [36]. There are no studies evaluating urinary RBP in PE; we reported the possibility of decreased tubular reabsorption in this disorder, although further research is needed to confirm it.

Another marker for the detection of proteinuria is the urine PCR, which corrects the proteinuria level by urinary excretion of creatinine and is helpful in the follow-up and treatment of proteinuric nephropathies. The evaluation of urine PCR has conflicting reports and its cutoff value has no uniform recommendation yet, though it could be a reasonable alternative to the 24-hour urine in pregnant women for diagnosing PE, avoiding the influence of variation in urinary solute concentration, and also a more convenient and rapid method [37], especially in severe PE [38]. Moreover, urine PCR may be a better screening test than the automatic dipstick urinalysis [39].

Urinary excretion of albumin is a risk factor for CVD and CKD, and it might indicate renal damage; hence, it is useful for monitoring patients with nephropathies [40].

Microalbuminuria is a known risk factor for vascular disease, and PE is associated with its high occurrence [41]. Pre-pregnancy microalbuminuria in type 1 diabetic women is also related to an increased risk of PE [42] and preterm delivery [43]. Either in PE or in diabetes, the metabolic control and the follow-up of microalbuminuria may improve pregnancy outcome [44].

Podocyte cells excreted in the urine are found in the presence of several kidney disorders and, although further studies are still needed, they might be used to differentiate PE from other glomerular disorders that involve hypertension and proteinuria after 20 weeks of gestation [2]. Recently, a study [21] raised the hypothesis that podocyturia may be present at the time of clinical diagnosis of $\mathrm{PE}$ and it may also be correlated with proteinuria as the excretion of these cells appears to be present in the acute phase of renal diseases. In our study, we did not find a significant difference between podocyturia in the CG and PE group, but we detected 3 cases in the PE group with about 4-fold the podocyturia of any other patient. It is possible that the renal lesion in these women was more intense, and they might have a future risk of CKD.

$\mathrm{PE}$ is an important cause of glomerulopathy worldwide [45], which might be an important clinical marker for increased risk of subsequent end-stage renal disease [46]. Renal filtration and function are affected in PE $[47,48]$ and might not completely recover immediately postpartum [49]. The early diagnosis of a glomerular disorder after PE supported by laboratory tests may provide prompt initiation of treatment and improve long-term outcome.

In summary, urinary RBP, urine PCR, albuminuria, and UAC ratio were elevated in the PE group in comparison to the CG. Considering the limitations of our sample size, podocyturia was not found to be a good predictor of $\mathrm{PE}$, although it might be associated with glomerular lesions after PE. These findings suggest that renal evaluation may add important information to the follow-up of glomerular injury in women whose pregnancy was complicated by $\mathrm{PE}$. More studies are needed for a better understanding of the mechanisms involved in PE and its systemic repercussions and, beyond that, to elucidate the relationship between these disorders.

\section{Acknowledgements}

This study was supported by the Kidney and Hypertension Hospital of São Paulo and Discipline of Nephrology of UNIFESP, the Brazilian Council for Scientific and Technological Development (CNPq), and the São Paulo Research Foundation (FAPESP), No. 08/56338-1. 


\section{References}

-1 Baumwell S, Karumanchi SA: Pre-eclampsia: clinical manifestations and molecular mechanisms. Nephron Clin Pract 2007;106:72-81.

-2 Karumanchi SA, Lindheimer MD: Preeclampsia and the kidney: footprints in the urine. Am J Obstet Gynecol 2007;196:287-288.

-3 Sibai BM, Dekker G, Kupferminc M: Pré-eclampsia. Lancet 2005;365:785-799.

4 Sass N, Sabino AT, Camano: Eclâmpsia; in Sass N, Camano L, Moron AF (eds): Hipertensão Arterial e Nefropatias na Gravidez. Guanabara-Koogan, 2006, pp 231-248.

5 National High Blood Pressure Education Program Working Group Report on High Blood Pressure in Pregnancy. Am J Obstet Gynecol 1990;13:1692-1712.

-6 Australasian Society for the Study of Hypertension in Pregnancy: Consensus statement - management of hypertension in pregnancy: executive summary. Med J Aust 1993;158:700-702.

7 Padden MO: HELLP syndrome: recognition and management. Am Fam Physician 1990;60:829-836.

8 Craici I, Wagner S, Garovic VD: Preeclampsia and future cardiovascular risk: formal risk factor or failed stress test? Adv Cardiovasc Dis 2008;2:249-259.

$\rightarrow$ Ronco P: Proteinuria: is it all in the foot? J Clin Invest 2007;117:2079-2082.

- 10 Hermes W, Franx A, Pampus MG, Bloemenkamp KW, Post JA, Porath M, et al: 10-year cardiovascular event risks for women who experienced hypertensive disorders in late pregnancy: the HyRAS study. BMC Pregnancy Childbirth 2010;10:28.

-11 Bellamy L, Casas JP, Hingorani AD, Williams DJ: Pre-eclampsia and risk of cardiovascular disease and cancer in later life: systematic review and meta-analysis. BMJ 2007;335:974-985.

-12 Thadhani R, Solomon CG: Preeclampsia - a glimpse into the future? N Engl J Med 2008;359:858-360.

13 Roberts JM, Taylor RN, Musci TJ, Rodger GM, Hubei CA, McLaughlin MK: Preeclampsia: an endothelial cell disorder. Am J Gynecol Obstet 1989;159:908-914.

14 Hladunewich M, Karumanchi SA, Lafayette R: Pathophysiology of the clinical manifestations of preeclampsia. Clin J Am Soc Nephrol 2007;2:543-549.

-15 Bujold E, Romero R, Chaiworapongsa T, Kim YM, Kim GJ, Kim MR, Espinoza J, et al: Evidence supporting that the excess of the sVEGFR-1 concentration in maternal plasma in preeclampsia has a uterine origin. J Matern Fetal Neonatal Med 2005;18:9-16.

-16 Chaiworapongsa T, Romero R, Kim YM, Kim GJ, Kim MR, Espinoza J, Bujold E, et al: Plasma soluble vascular endothelial growth factor receptor-1 concentration is elevated prior to the clinical diagnosis of pre-eclampsia. J Matern Fetal Neonatal Med 2005;17:3-18.

17 Romero R, Nien JK, Espinoza J, Todem D, Fu W, Chung H, Kusanovic JP, et al: A longitudinal study of angiogenic (placental growth factor) and anti-angiogenic (soluble endoglin and soluble vascular endothelial growth factor receptor-1) factors in normal pregnancy and patients destined to develop preeclampsia and deliver a small for gestational age neonate. J Matern Fetal Neonatal Med 2008;21:9-23.

-18 Gu Y, Lewis DF, Wang Y: Placental productions and expressions of soluble endoglin, soluble fms-like tyrosine kinase receptor-1, and placental growth factor in normal and preeclamptic pregnancies. J Clin Endocrinol Metab 2008;93:260-266.

-19 Stillman IE, Karumanchi SA: The glomerular injury of preeclampsia. J Am Soc Nephrol 2007;18: 2281-2284.

-20 Collino F, Bussolati B, Gerbaudo E, Marozio L, Pelissetto S, Benedetto C, Camussi G: Preeclamptic sera induce nephrin shedding from podocytes through endothelin-1 release by endothelial glomerular cells. Am J Physiol Renal Physiol 2008;294:1185-1194.

-21 Garovic VD, Wagner SJ, Turner ST, Rosenthal DW, Watson WJ, Brost BC, Rose CH, et al: Urinary podocyte excretion as a marker for preeclampsia. Am J Obstet Gynecol 2007;196:320.el-e7.

-22 Hara M, Yanagihara T, Kihara I, Higashi K, Fujimoto K, Kajita T: Apical cell membranes are shed into urine from injured podocytes: a novel phenomenon of podocyte injury. J Am Soc Nephrol 2005; 16:408-416.

-23 Holt JL, Mangos GJ, Brown MA: Measuring protein excretion in pregnancy. Nephrology (Carlton) 2007;12:425-430.

24 Coelho TM, Martins MG, Vianna E, Mesquita MR, Camano L, Sass N: Proteinuria in hypertensive syndrome of pregnancy: maternal and perinatal outcome. Rev Assoc Med Bras 2004;50:207-213.

25 Pereira AB, Kirsztajn GM: The clinical pathology laboratory and the screening of renal diseases. J Bras Nefrol 2007;29:13-17. 
-26 McDonald SD, Han Z, Walsh MW, Gerstein HC, Devereaux PJ: Kidney disease after preeclampsia: a systematic review and meta-analysis. Am J Kidney Dis 2010;55:1026-1039.

-27 Sibai BM: The HELLP syndrome (hemolysis, elevated liver enzymes, and low platelets): much ado about nothing? Am J Obstet Gynecol 1990;162:311-316.

-28 Zanella MT: Microalbuminúria: Fator de risco cardiovascular e renal subestimado na prática clínica. Arq Bras Endocrinol Metab 2006;50:313-321.

- 29 Pereira AB, Nishida AK, Vieira JG, Lombardi MT, Silva MS, Ajzen A, et al: Monoclonal antibodybased immunoenzymometric assays of retinol-binding protein. Clin Chem 1993;39:472-476.

- 30 Price CP, Newall RG, Boyd JC: Use of protein:creatinine ratio measurements on random urine samples for prediction of significant proteinuria: a systematic review. Clin Chem 2005;51:1577-1586.

-31 Methven S, Macgregor MS, Traynor JP, Hair M, O’Reilly D, Deighan CJ: Comparison of urinary albumin and urinary total protein as predictors of patient outcomes in CKD. Am J Kidney Dis 2011;57:21-28.

- 32 Vaisbuch E, Romero R, Tovi SM, Kusanovic JP, Chaiwoapongsa T, Dong Z, et al: Maternal plasma retinol binding protein 4 in acute pyelonephritis during pregnancy. J Perinat Med 2010;38:359-366.

- 33 Vaisbuch E, Romero R, Mazakitovi S, Erez O, Kim SK, Chaiworapongsa T, et al: Retinol binding protein 4 - a novel association with early-onset preeclampsia. J Perinat Med 2010;38:129-139.

-34 Masuyama H, Inoue S, Hiramatsu Y: Retinol-binding protein 4 and insulin resistance in preeclampsia. Endocr J 2011;58:47-53.

- 35 Beetham R, Dawnay A, Menabawy M, Silver A: Urinary excretion of albumin and retinol-binding protein during normal pregnancy. J Clin Pathol 1988;41:1089-1092.

-36 Gerö G, Anthony F, Rowe DJ, Dennis KJ: Increased urinary excretion of retinol-binding protein during normal pregnancies. Clin Chem 1986;32:916-917.

37 Shahbazian N, Hosseini-Asl F: A comparison of spot urine protein-creatinine ratio with 24-hour urine protein excretion in women with preeclampsia. Iran J Kidney Dis 2008;2:127-131.

-38 Aggarwal N, Suri V, Soni S, Chopra V, Kohli HS: A prospective comparison of random urine proteincreatinine ratio versus 24-hour urine protein in women with preeclampsia. Medscape J Med 2008; 10:98-105.

- 39 Dwyer BK, Gorman M, Carroll IR, Druzin M: Urinalysis vs urine protein-creatinine ratio to predict significant proteinuria in pregnancy. J Perinatol 2008;28:461-467.

-40 Miller WG, Bruns DE, Hortin GL, Sandberg S, Aakre KM, McQueen MJ, et al: Current issues in measurement and reporting of urinary albumin excretion. Clin Chem 2009;55:24-38.

-41 Bar J, Kaplan B, Wittenberg C, Erman A, Boner G, Rafael ZB, et al: Microalbuminuria after pregnancy complicated by pre-eclampsia. Nephrol Dial Transplant 1999;14:1129-1132.

-42 Jensen DM, Damm P, Ovesen P, Pedersen LM, Nielsen HB, Westergaard JG, et al: Microalbuminuria, preeclampsia, and preterm delivery in pregnant women with type 1 diabetes. Diabetes Care 2010;33: 90-94.

43 Ekbom P, Damm P, Rasmussen BF, Rasmussen UF, Molvig J, Mathiesen ER: Pregnancy outcome in type 1 diabetic women with microalbuminuria. Diabetes Care 2001;24:1739-1744.

-44 Nielsen LR, Damm P, Mathiesen ER: Improved pregnancy outcome in type 1 diabetic women with microalbuminuria or diabetic nephropathy. Diabetes Care 2009;32:38-44.

-45 Henao DE, Saleem MA, Cadavid AP: Glomerular disturbances in preeclampsia: disruption between glomerular endothelium and podocyte symbiosis. Hypertens Pregnancy 2010;29:10-20.

-46 Vikse BE, Irgens LM, Leivestad T, Skajaerven R, Iversen B: Preeclampsia and the risk of end-stage renal disease. N Eng J Med 2008;359:800-809.

-47 Moran P, Baylis PH, Lindheimer MD, Davison J: Glomerular ultrafiltration in normal and preeclamptic pregnancy. J Am Soc Nephrol 2003;14:248-652.

48 Maynard SE, Thadhani R: Pregnancy and the kidney. J Am Soc Nephrol 2009;20:14-22.

-49 Hladunewich MA, Myers BD, Derby GC, Blouch KL, Druzin ML, Deen WM, et al: Course of preeclampic glomerular injury after delivery. Am J Physiol Renal Physiol 2008;294:F614-F620. 